\title{
THE COUNTERPOINT OF EARTH AND WORLD MEANINGS IN THE NATIONAL IDENTITY' EXPRESSION
}

Edvardas ČIULDĖ, Department of Philosophy, Psychology and Professional Educology, Universiteto str. 10, Akademija, Kaunas district, Lithuania; edvardas.ciulde@ asu.lt (corresponding author)

Asta STEIKŪNIENĖ, Department of Philosophy, Psychology and Professional Educology, Universiteto str., 10, Akademija, Kaunas district, Lithuania; asta.steikuiene@asu.lt

The meanings of the earth and the world can be associated with issues of national identity. In the article, the issues of fostering national identity are discussed in the context of M. Heidegger's philosophy's outlook on a land and world disputes. The article tries to define how much a nation can be an object of scientific cognition. Understanding the nation as a resistance to limiting objectification is a methodological background to the development of the topic, which obliges the philosophical interpretation of the problem to be trusted, at least as a scientific reduction of the problem. Sketches of the earth and the world we use as a kind of catalysts of intellectual imagination and methodological guides.

The main aim of the article is the attempt to analyze the conditions of the expression of the national identity in terms of both the subject matter and the non-objective reflection, where different approaches complement each other (what we call by the term "counterpoint", borrowed from the theory of music). The collision of national identities through Martin Heidegger's typology of images has not been examined before. There are also discussed the untapped reserves for nurturing Lithuanian identity - both spiritual and economic. The aim is to refine the political awareness of the Public Treaty model raised by the Enlightenment thinkers.

Land is an important factor in the economic development of a so ciety and the object of economic exploitation, but, more importantly, it is a standpoint in establishing and maintaining the nation's vitality. The dispute between the earth and the world which foster the thesis of national identity acquires the essence of the truth of being.

Keywords: earth, identity, nation, world, public contract, state, thesis.

\section{INTRODUCTION}

The problems of nation and identity had been are analysed in various aspects-sociological, philosophical, historical, and political. The question of such a type we had raised too -can a nation become a subject of knowledge? (Čiulde, E., 1999). We can start with the fact that nation is not the same as society in the common meaning of the word; therefore, sociology could reflect it to a very small extent. What's more, the classification of sciences envisages a discipline like ethnology, which, according to the etymological meaning of this name, we can define as the science of the nation. The initial acquaintance with the field of ethnological researches makes it clear that the "ethnos" here means "an alien nation". Therefore, ethnology, as a branch of cultural anthropology, which usually interprets the self-expression of ethnographic peoples from a comparative point of view, has little in common with the task of fostering national identity and focusing to the "recognition" theme of its own people.

We cannot look to our own nation as to the object of scientific knowledge to the fullest, since we never be able to be objective in relation to our own people. This awareness of the nation is a methodological background to the development of the topic, which obliges to rely on a philosophical interpretation no less as scientific reduction of the problem. The discussion of this concept is like a crossroads between the interpretation of a philosophical phenomenon and the reconstruction of a scientific object, balancing, if you could say, on the razor blade, preserving this tension as a condition for dynamic discussion of the problem, without pre-prepared passive schemes.

From the point of view of phenomenological ontology, the way itself of the nation's existence in the world does not allow to represent national identity in the usual concepts of the contradiction between subject and object without loss, without detracting from the extreme one-sided object' construction or subjective perspectives of manipulation. More importantly, it must be noted that, in such a case, we would be obliged to choose one of the aforementioned perspectives, excluding the other outside of legality, while losing understanding of the being' tension in the expression of national identity. Thus, the objectivity of the proposition of the scientism canon is not so cherished ideal here, which we should keep. Indeed, sometimes a talented poet's strophe tells more about the idea of a nation than entire scientific tracts on such an extremely sensitive issue.

Copyright (C) 2017 The Authors. Published by Aleksandras Stulginskis University. This is an open-access article distributed under the terms of the Creative Commons Attribution License (CC-BY 4.0), which permits unrestricted use, distribution, and reproduction in any medium, provided the original author and source are credited. 
Anyway, here is not going to give up the rational orientation of the topic and not intended to change the concepts to metaphors, but only aim at pointing at least a few points on the way to a more diverse understanding of the nation's idea and discussion of conditions for nation identity expression. This is the primary, motivating choice of the topic, while simultaneously raising the task of finding the most appropriate means for achieving such a goal.

As has been said, the division of subject-object into the scientific discourse is inappropriate in our case (or only partially only), because in this way we lose the live synthetic understanding of the thematic phenomenon, and it is not applicable here, with regard to the expression of national identity with its contradictions and new challenges. Heidegger seems to have a more intense image of such a tension in a great deal about an earth-world dispute. Heidegger's interpretation of earth and world as a starting point for national identity dispute seems to be self-evident, but by our own wonders, we must confess the fact that we will be the first to declare the conflicts of national identity revealed by Heidegger's earth and world typology. Thus, in the introduction, we must present as accurately as possible the definitions of the Heidegger's interpretation of earth and the world as a peculiar road mark in the journey of the proclamation of our national identity.

As Heidegger writes, "the earth every attempt to invade into it forces to collapse" (Heidegeris, 1980, p. 230). He talks clearer: "It makes every single purely mathematical curiosity a nuisance. The latter may seem to be the domination and progress of the scientific and technical knowledge of nature, but that dominion is merely the helplessness of desire. Frankly speaking, the earth appears to itself only if it is considered largely unidentified, when it avoids any explanation and remains eternally closed" (Heidegeris, p.230). In turn, "The world is a continuous openness of wide open roads, and these roads are simple and fundamental decisions in the nation's historical destiny." How do these meanings fit or are inappropriate with each other? "The world and the earth are essentially different from each other, but they are not inseparable ... The world itself thinks in its essence to surpass the earth. It, constantly opening, does not tolerate any confinement. And the earth, hiding everything, tends to seize the world and save itself" (Heideggeris, p.231).

As is known, parallel discussion of the earth and the world meanings arises when of M. Heidegger analyses the nature of the work of art (Heidegeris, 2003). On the other hand, the transfer of Heidegger' statements to the national identity collision is by no means a mechanical transposition, which does not arise without assessing the peculiarities of different spheres of reflection. It seems that the opposite, namely, the Heidegger's interpretation of the earth and the world, in the context of discussing the expression of national identity, gives additional suggestibility to such unclose / close of dichotomy, because here the earth and the world's symbolism is discussed in their natural place.

The main purpose of the article is to describe the conditions of national identity expression-factual and nonfactual. We use Heidegger's land' and world' meanings as methodological guides and a kind of catalysts of intellectual imagination, what the term borrowed from the theory of music "counterpoint" defines (the counterpoint is a combination of several different melodious lines playing together). Such reciprocity obliges not to give up the easiest task for schematization. One must discipline oneself, because of transferring the problem into a sphere of knowledge could dispel the essence; so, we pay more attention to the problems of the awareness of the reflection of nationality, the higher or lower significance of behind-the-scenes factors.

\section{The subject of discussion is the expression of national identity in the context of earth and world traditions (in Heidegger's interpretation).}

\section{RESULTS AND DISCUSIONS}

\section{The Thesis of Identity}

We want to start with an extremely basic question - what unites us, Lithuanians? Let us try to imagine that our question is not rhetorical, not confronted with pre-knowledge. On the other hand, we can talk about such ignorance without larger complexes, because, in any case, we really know that the ignorance or partial knowledge mentioned here, does not destroy the object, to which itself is oriented (as a paradox); we usually guarantee our national identity in advance. Pre-reflexive nature of the national identity is evidenced by the words we use in our frequent speeches, such as the love to motherland we receive with mother's milk, the motherland itself is the most precious value, and we are only grateful (or not) children of it, and so on. The development of the topic involves as inevitable satellites various banalities, monotonous tautological expressions. It does not mean the unimportance of the topic, but, on the contrary, the uncontrolled flow of words, created by excessive emotions, is a sign of the exceptional significance of this topic and testifies the need for a constant return to the question. Therefore, actualization of such a question appears as an internally needed pathos.

As has already been mentioned, the example of tautology is of great importance. We often say that we all share the same homeland, so I am Lithuanian because I am Lithuanian (A is A, because A = A). Indeed, this answer is very persuasive and implies something like blocking further questioning. Tautological answer in principle is always fruitful response. By the way, we can note that such a dignified doctrine as Platonism, which speaks about distinct conception of being, is the theory of tautology par excellence. Tautology directly becomes an ontology here, because the identity of the thing, its principal equality to itself refers here, as the main attribute of the reality of the thing; and the object that loses identity is we understand as unreal thing, some kind of ghost being without space. For example, the unconscious Platonism in our everyday lexicon, which is our favorite to repeat and becomes a language tautological enchantment, is Kaunas is Kaunas. Such a tautological saying announces that additional comment on "what is Kaunas" is unnecessary; further explanation can drown the essence. However, there is some kind of affirmation because of acknowledgement in advance that Kaunas is strong by its identity, or, in other words, by it is tautology.

On the other hand, tautology always is a productive answer, but by its very nature, an extremely poor answer. In order to expand the example of tautology, it seems we can try only a negative way, for example, saying that I am 
Lithuanian because I'm not Russian, I'm not a Zulus, and so on, I.e. listing all known nationalities (A is A, because A is not equal to $\mathrm{B}$, to $\mathrm{C}$, etc.). In this case, identity we acquire in the context of all (potentially endless) diversity, with greater or lesser success in attemt to master this diversity in the context of a global world.

However, it seems that in this case tautology retains in principle monotony, because the tautological response is a very static answer. We must ask, if a tautological response can be different, and it seems that the example of a dynamic tautology one can find in this type of statement: I am Lithuanian as long as I am Lithuanian. In this case, inevitably, I am obliged to explain the changing factors that determine the establishment of the Lithuanian identity, as well as dispersal and loss.

Such an identity is not a result of isolated self-perception but the result of being in common with other people. So what unites us, Lithuanians? The territory, history, historical memory, culture, language, the struggle for an independent state and political life? What is really extremely important, and what is only as an insert derivative? There were many attempts to answer this question, so scientific and publicist publications on this topic are incredibly rich and varied. However, it is not easy to discuss with some our people, who are convinced that a choice "to be Lithuanian" is a very limited choice in the age of globalization; the belief exists that status of Europeans is much more important and opens up boundless liberation of mentality.

The definition of human identity always focuses on a specific, unique reality, while references such as "I am a European" are classifiers, cataloguing indexes. In today's universe dispute, it seems that most of us would still support the notion that there is no "tree in general", because we are convinced that there is actually only birch, oak, lime, and so on. What is more, the sequences of the universalisation mentioned here (tree, European, etc.) are not just an empty sound, they refer to the realm of reality, for example, it can be said that the oak is a tree, not a shrub, a Lithuanian is a European and not as Asian and so on. However, we cannot replace the identity by convenient generalizations. Without such a realistic point of reference, abstract identity is dying and eventually disappears.

Moreover, when we raise the question of the formula of identity, it would be impossible to bypass Parmenides' statement about the identity of thought and being and the example of tautology that is emerging here: the being is a thought about being and the thought of being is being (Parmenides 1991). Many times people had asked these questions - how the thought and substance may coincide, and when such an identity is possible. Now we can ask in another way where such an identity is possible. Our answer to the above question is this: the thought and the substance coincide in the same thing, (in greek: to auto, tauto). On the other hand, we do not deny that the "auto" remains a mystery.

As Heidegger says, commenting the identity passage of Parmenides: "The basic word of the thesis of Parmenides is to auto and remains unclear. Let us leave it unclear. However, let the thesis, which is at the beginning, to give us some sort of hint at the same time "(Heidegger, 1992, p. 334).

A specific hint to solve this identity puzzle gives for us the Lithuanian language or, more precisely, the play of words, which appears between the Greek words to auto, tauto and the Lithuanian word "tauta" (nation). The play of words, the alleged lack of coincidence and collision between two different languages only covers the fundamental seriousness of the answer, that the being and thinking of the people is the same (in greak -to auto, tauto, in Lithuaniantauta). In other words, we find the reference that truth of being is possible only in in the native language.

No doubts, knowing foreign languages is an important part of human education, enabling us to expand communication opportunities. In fact, it is possible to learn the language, but to think and touch the secret of being together is possible only on the horizons of the mother tongue.

H.-G. Gadamer suggests that philosophy is primarily a matter of lack of speech (Gadamer, 1999). A famous philosopher draws attention to the fact that it is not enough to tell the decisive intuitions of philosophy in the everyday use of words. It is easy to presume that Gadamer speaks about a language shortage or failure that we can only foster and understand in the context of the mother tongue. It seems that developer of hermeneutical philosophy did not have a negative attitude to the foreign languages learning or the richness of the vocabulary available in such languages. The example is also applicable here, so that the prosthesis did not hurt. H.-G. Gadamer emphasised the relevance of the philosophical language to the themes of philosophy. Philosophers should raise an ambitious task in the discussion of the essential problems to say no less as poets in several lines (for example, Friedrich Holderlin).

The native language embodies the tension of the earth and the world in the most appropriate way, since only the native language simultaneously allows them to spread to new horizons and together keep the memory of a dynamic national identity. In addition to everything else, it means that the etymology of the native language in order to enable thoughtfulness is an equally important point of resilience as the universal rules of logic to ensure the formal correctness of the thought.

\section{Untapped reserves for nurturing Lithuanian identity}

There are many discussions- in different ways and at different levels- dedicated the problem of Lithuanian identity fostering and preserving. In fact, there is already no retreat, because the issue of identity preservation is actual in extreme form. Apart from the typical challenges posed by globalization to each nation, the foundations of the vitality of the Lithuanian nation erodes and destroys the emigration flows of a huge scale. Together with other problems, emigration has actually been the basis for the physical survival of the nation. Thus, if to be a Lithuanian is a precious and honourable value, the question is how to prevent the destruction of Lithuanian identity and the nation.

We have already mentioned the significance of the development of Lithuanian identity in the mother tongue, which combines the openness of the world and the closure of the earth. Indeed, when Lithuanians are scattered all over the world and become a significant part of the Lithuanian nation, the language factor becomes even more important than usual. Language and commitment to national symbols, so, the ideal motive for preserving identity, begins to play an even bigger 
role than before. As it seems, the law of balance is also valid here; or in other words, for expression of the spirit, we need the carnal assumptions too. It is easy to imagine a situation when people study Lithuanian language in the world's most famous universities, after the Lithuanians themselves do not exist. Such a fantastic prospect is not favourable for today's Lithuanian, who really understands that no nation exists for language, but language for the nation.

The economic approach is important in discussing this topic, and sometimes obtains exclusive rights, because of the scale and controversy of the emigration that began. In recent decades, emigration is essentially economic emigration. People go abroad to look for better earnings and to improve their living conditions. Some of them will stay in countries offering economic asylum and better living standards; but it is likely that with the improvement of the economic situation in Lithuania itself, this kind of emigration flows will reduce to a minimum or even a reverse re-emigration process will begin. Similarly, it would be possible to think about the promotion of births by increased benefits and benefits for pregnant women, when the state, after the economic recovery will be richer, more economically capable. However, we would like to draw attention to the economic factors that foster the identity of the nation, which the state had left unused or lost. The discussion is meaningful even if the process becomes irreversible and we cannot avoid losses. In this case, perhaps the most important lesson is that it allows us to look for a more balanced solution in the field of parallel activities.

When we talk about the conditions for the preservation of Lithuanian identity, it would seem that we did not have the slightest pretext to talk about the institute of private property. It is customary to assume that private property law is not the basis of unity, but merely the reason to divisibility, separation, mutual alienation, rivalry or even antagonism. However, even to the most dogmatic Marxist will be difficult to deny that the institute of ownership has directly served the emergence of a nation. On the other hand, the question of property we must always analyse in the context of specific historical circumstances.

The adoption of major shopping centres may become a limiting factor for private property, although it seems like a certificate of success in capitalization and a free market label. Everyone is witnessing this cumbersome event, when the multiplication of gigantic ultramodern supermarkets had directly destroyed, with a few exceptions, the economic and culture world of small shops and small points of sale. In turn, we are convinced that in this sphere, the Institute of Private Property always manifests itself in the most intense form and becomes, in metaphorical terms, the glue of the nation.

Of course, we can argue that such Gulliver type trading organization is better in terms of management and allows the optimization of the buyer-seller relationship. However, as we know, in Western European countries, such permanent shopping centers are functioning in a framed manner, providing operational opportunities only at the edges of the city, with limiting hours of work, etc. Undoubtedly, these restrictive measures are socially motivated, i.e., by marking separate traffic conditions for large, Gulliver type organizations and aiming to preserve the possibilities of safe traffic for small producers and traders. This problem in Lithuania reminds the task of preserving national identity and the integrity of the nation in general. The point is that in a completely open world, small private property is tied to the place, which is the main assumption of an in-depth (that is, emerging from the ground) sedentary. As a rule, big business in an open world has an international nature, aiming to go beyond all boundaries and circumstances. Thus, even without neglecting too much color, we can say that just a small business is one of the most important realization of the idea of the Homeland, also realizing that business empires often obscure the idea of a Homeland by subordinating it to abstract relations of hired labor and capital. The reference to trade megacities is particularly important here as an analogy, that allows us to point out the fact that this type of contradiction is even more evident in the land market, where, according to Plato, we can see the same on the big board and written in uppercase letters.

Earth is not really material, but the shape of forms (Čiulde, 2013), but it is also true that the earth is an immediately tangible reality, the "most sensitive thing" in the world.

The image of the earth, in particular, allows you to manifest the experience of attachment to the place, rooting. This is especially important for Lithuanians, who are essentially descendants of peasants. It means that the land is important not only in the sense of a romantic; the land itself bounds the Lithuanian by the obligation to take care of it, therefore, by the land ownership right. Lithuania has long been a country of landowners and the man first is the owner of the land. Therefore, it is particularly disappointing that land ownership issues in Lithuania are sometimes still not clear.

As we know, the right to move the property of the land has created an insatiable slough of corruption, so far, has allowed not one wicker to profit in the most cynical way. It is very sad that the law allowed such practise. Still even more dangerous seems the practice of land accumulation in Lithuania, when thousands of hectares are appearing in one hands.

It is possible to say that the land concentration is a main factor of progress, which enables effective use of the latest technologies, cost optimization and maximum efficiency of work. We can close the eyes to the fact that the big agricultural enterprises destroy the diversity of life and challenge, for example, the possibility of organic farming. In fact, such economic activity is complicated to in Lithuania due to many historical cultural, landscapes, demographic factors. Therefore, we can safely assume that the land in Lithuania is being concentrated for speculation purposes. The situation raises the question - who is the real owner of the land in Lithuania today and, much more-who will become such an owner after decades? If to observe the situation passively, things can turn around in such a way that our country will become a place for the disposal of harmful waste from foreign countries, or, for example, a total pig farms complex from Klaipeda to Vilnius. Therefore, the question is whether the pessimistic scenario of events that is drawn deals with the truly irreversible trends in the global world and how much globalization processes causes this scenario.

We often see the danger of globalization primarily in terms of standardization of life, unification, and the elimination of differences. We are convinced that such global standardization creates a terrible monotony and destroys cultural diversity. This is partly the correct finding, but such globalization draws attention to such things as clean air, clean water, chemically unpolluted land, space, greenery, primordial forests. 
It would be worth to mention the fact that standardization associated with globalization processes in the sphere of social welfare obliges the responsible institutions of the country to focus on the best examples. This kind of standardization is associated with a certain civilization of society, a type of sensation. Finally, it is necessary to state openly, that the greatest threat to the integrity of the nation today is poverty; social exclusion for a small nation is a burden of excessive imbalances. If we notice that the political power of our country more active represents the interests of the ultra-large capital, the monopolies, it's time to remember that we have levers in our hands that allow us to "raise" the power that it would be essentially focused on serving for national interests. Openness to the world and orientation towards the standards of Western political culture for implementation of such a task is not a disturbing, but just a boosting circumstance. Therefore, we can ask this question in another way - how to deal with political alienation in Lithuania?

\section{The Nation and the State}

There is widely spread opinion that Karl Marx discovered the political alienation. However, we must note that the definition of political alienation in social discourse much earlier than Marx had introduced the philosophers, ideologists and thinkers of Enlightenment age, commonly referred to as educators. However, even more important that the theory of Public contract raised by educators foresees specific ways to overcome this alienation. The educational philosophical provisions are chosen here as the starting point for their closeness to the "earthly" worldview. The educators were rational, but as we know, their rationalism was special, focusing on a prudent example of nature. It differs fundamentally from later methodologist's outlook that intelligence is an example of scientific knowledge of nature.

The theory of Public contract discusses the transition of a person from the natural to the political state, emphasizing people' more or less conscious conviction that they need a public agreement as legal and political regulation of human relations. Thus, the state can appear in different ways, but it remains as it only finds its foundation in people's consciousness; in that sense, the public contract continues until the fundamental grounds of political organization are substantially denied.

More specifically, the individual treats public contract as the expropriation of all his natural rights for the benefit of the community. However, such an expropriation is not a loss, since each contractor in such an agreement acquires all the things that he himself gives away to another. Everyone obeys the same conditions imposed for others.

The theory of a public contract does not envisage a social contract as an empirical fact; such a Treaty is understood more as a transcendental fact of consciousness (the definition of "transcendental" meaning defined by I. Kant's philosophy) than a concrete empirically fixed event. However, the recognition of the significance of this theory requires an intensification of discussions and the search for answers while raising demands to the authorities in accordance with the existing standards of Western political culture. It is necessary to develop an understanding that the nation can immediately cancel the mandate of government if society believes that the government acts non-compliance with the Treaty. It seems this Agreement (or agreements) culture develops very slowly in Lithuania, although during the formation an independent Lithuanian state this idea had the broadest support. We are not talking about party agreements or meetings, but about the social contract in a more fundamental sense, about a Treaty that can potentially touch the minds and hearts of every citizen, and thus an unwritten agreement that does not give anyone the exclusive right to alienate the state to their advantage. Even the most successful bureaucracy and administrative development of social processes cannot substitute for such a Treaty deficit. In the absence of such processes as a Treaty, a government with more or less positive work in the organization of society, together, inevitably creates a negative alienation landscape.

It important to note that the transcendental nature of the Treaty does not conflict with the day-to-day, obvious testimony of such a treaty. Therefore, educators do not want to see anything that is beyond human and thus, alien to human nature. The pathos of educators-all that matters must be included in the dialogue, all that participates in the dialogue is meaning, that does not match, are anomalies.

It is also worth noting that the commitment to the idea of science manifests here by the belief that science can become important only through the mediation of human consciousness.

Jean-Jacques Rousseau points out that this unwritten treaty is of such nature that the very least, a microscopic breach of contract, can destroy the entire contract (Rousseau, 2015). The emphasis here is not so much on quantitative expressions (small, large, frequent, rare, etc.), how much whether the very principle that requires to adhere the same conditions, which we impose on others, is not violated. The public contract does not contain any excessive desires, caprices, or any unnecessary motions to one side or the other; in fact, such a treaty rests on the most rigorous formula: no one can demand from another such victim, which is not determined to give himself.

As it seems to us, the theory of a social contract is not just a series of apologetic argumentation, which proves that political and legal organization of society is necessary. In fact, the concept of a public contract as a projector highlights the negative landscape of the problem and obliges to raise the question - why the resources of the agreement in society are diminishing and horrible irritation is growing? Tautological answer is as follows: the mechanism of the public contract in our tide is in dire straits due to the elimination of equal opportunities and protectionism, and thus the expression of fierce nepotism, blocking such a treaty by the clan interests, and in particular the expropriation of state institutions in favor of the groups.

Contract theory of the society is also interesting in the context of which one of the founders, namely J.-J. Rousseau notices, that public contract is broken when citizens are voting feet and leave the country's territory, choosing a place of residence in the territory of another country (Rousseau, 2015). However, we should not equate the territory with the earth in the meaning of that word. For the Lithuanian nation, becoming partly an extraterritorial nation, the image of the land as a symbolic unity becomes even more significant and invites to gather the idea of a nation for people from different 
territories. For both Lithuanians living in Lithuania and Lithuanians of the world who reside in other countries, Lithuania is primarily a promised land.

\section{CONCLUSIONS}

1. National identity topic limited the context of Heidegger's Earth and World meanings requires challenging the ontological tension of the problem without pre-prepared schemes of subjective or objective configuration.

2. Application of Earth and World meanings borrowed from Heidegger' fundamental ontology for nation contemplation let us avoid the confusion when nation as an object is often referred as enslaved nation, and as the subject we often mean independent, liberated itself nation. The use of subject and object concepts when we talk about the nation, does not allow completely separate political assessments from the heuristic references and methodological guides. In turn, the meanings of the earth and the world are such provocative images, which justify an attempt to move beyond the usual dividing line between factual and non-factual knowledge.

3. Land is an important factor of society' economic dynamics, but not only an object of economic exploitation. The land is the basis for consolidation of nation's vitality. In turn, the world, even in the context of the processes of globalization, should not be understood as a factor, which limits the fostering of national identity or threat to the preservation of national innocence. The Earth and World dispute in Heidegger' interpretation highlights the new possibilities to foster national identity.

4. Fostering the thesis of national identity in the dispute between the Earth and World acquires the essence of the truth of being.

\section{REFERENCES}

1. Aristotelis, 2009. Politika (Politics). Vilnius. Margi raštai. [In Lithuanian]

2. Čiuldè, E. (2013). Žemès prasmèvaizdis ir „pasiklydusio“valstiečio kolizija (Understanding the Earth and a Collision of "Lost” Peasant). Kultūros barai, Nr. 12. [In Lithuanian]

3. Čiulde, E. 1999. Ar tauta gali tapti pažinimo objektu? (Can a nation become a subject of knowledge?). Humanistika, Nr. 2 (4).

4. Dilthey,W. 1990. Hermeneutikos atsiradimas (The Emergence of Hermeneutics). Filosofija ir sociologija, Nr.1. [In Lithuanian]

5. Gadamer, R. 1999. Istorija. Menas. Kalba (History. Art. Language). Vilnius: Baltos lankos. [In Lithuanian]

6. Grondin, J. 2003. Filosofinès hermeneutikos ịvadas (Introduction of Philosophical Hermeneutics). Vilnius: Aidai. [In Lithuanian]

7. Hegel, G. 1997. Dvasios fenomenologija (Phenomenology of Spirit). Vilnius: Pradai. [In Lithuanian]

8. Heidegeris, M. 1992. Rinktiniai raštai (Selected writings). Vilnius: Mintis. [In Lithuanian]

9. Heideger, M., Gadamer, R. 2003. Meno kūrinio ištaka (The Origins of Art).Vilnius: Aidai. [In Lithuanian]

10. Heidegger, M. 2014. Būtis ir laikas (Being and Time). Vilnius Gedimino Technical University Press „Technic“.[In Lithuanian]

11. Rousseu, J-J. 2015. Visuomenès sutartis arba politinès teisès principai (A Public Contract, or the Principles of Political Law). Vilnius. Vaga. [In Lithuanian]

12. Parmenidas, 1991. Apie prigimtị (About the Nature). Naujasis židinys, Nr. !0. [In Lithuanian] 